\title{
Manipulating the Attractiveness and Suitability of Hosts for Diamondback Moth (Lepidoptera: Plutellidae)
}

\author{
FRANCISCO R. BADENES-PEREZ, BRIAN A. NAULT, AND ANTHONY M. SHELTON
}

Department of Entomology, Cornell University, New York State Agricultural Experiment Station, 630 W. North Street, Geneva, NY 14456

\section{J. Econ. Entomol. 98(3): 836-844 (2005)}

\begin{abstract}
Ovipositional preference and larval survival of the diamondback moth, Plutella xylostella (L.), were compared among cabbage, Brassica oleracea L. variety capitata; glossy collards, Brassica oleracea L. variety acephala; and yellow rocket, Barbarea vulgaris ( $\mathrm{R}$. Br.) variety arcuata in different treatments of planting density, host plant age, intercropping, and water stress in 2003 and 2004. P. xylostella laid nearly twice as many eggs per plant in the high planting densities of glossy collards and yellow rocket than in the standard planting densities. Ovipositional preference was positively correlated with plant age in cabbage, glossy collards, and yellow rocket. Larval survival on cabbage was 1.9 times higher on 6 -wk than on 12 -wk-old plants, whereas larval survival on collards was 12.1 times higher on the younger plants. No larvae survived on either 6- or 12-wk-old yellow rocket plants. Intercropping cabbage with either tomato, Lycopersicon esculentum Mill., or fava bean, Vicia fava L., did not reduce the number of eggs laid on cabbage. No significant differences in oviposition were found between water-stressed and well-irrigated host plants treatments. Yet, P. xylostella larval survival on water-stressed cabbage was 2.1 times lower than on well-irrigated cabbage plants. Based on our findings, the effectiveness of trap crops of glossy collards and yellow rocket could be enhanced by integrating the use of higher planting densities in the trap crop than in the main crop and seeding of the trap crop earlier than the main crop.
\end{abstract}

KEY WORDS Plutella xylostella, yellow rocket, glossy collards, tomato, water stress

CULTURAL PRACTICES CAN HAVE complex and significant impacts on insect population dynamics (Poswal et al. 1993). Understanding how cultural practices affect pest population dynamics is important for developing sustainable and environmentally friendly approaches to pest management, especially in cases where insecticides are either avoided or not available (e.g., subsistence farmers in developing countries). Resistance to insecticides is another important factor that has triggered the exploration of cultural control practices for pests such as the diamondback moth, Plutella xylostella (L.) (Talekar and Shelton 1993, Hooks and Johnson 2003).

The level of damage that $P$. xylostella inflicts on crops is largely dependent on female ovipositional preference choices (host attractiveness) as well as larval survival (host suitability). If factors known to alter the attractiveness and suitability of a host for female P. xylostella and their progeny can be identified, they could be exploited through cultural practices.

Higher planting densities could increase attraction and retention of $P$. xylostella, resulting in increased oviposition on the host. This scenario is an example of the resource concentration hypothesis, which proposes that insect herbivores, particularly specialists, are more likely to find and remain in hosts that are concentrated, and which has been tested with different insect pests (Root 1973). For example, P. xylostella adults were more attracted to large than to small groups of collard plants (Maguire 1983). Ovipositional preference also is affected by plant age, with older plants sometimes preferred over younger plants (Leyva et al. 2000, Spangler and Calvin 2000; but see Smyth et al. 2003a). Older plants tend to be larger and may offer more stimulating visual cues because of greater leaf areas and different amounts and composition of volatiles released (Tollsten and Bergstrom 1988, Choi et al. 2003). Larval survival also has been shown to be affected by plant or leaf age (Raupp and Denno 1983, Klemola et al. 2003, Smyth et al. 2003b). Older leaves may be less nutritious and less suitable for larval development and survival (Watt 1987, Raupp et al. 1988, Kause et al. 1999). Feeding on older leaves can also increase mandibular wear because of their increased toughness (Larsson and Ohmart 1988, King et al. 1998)

Plant water status also can have a significant effect on ovipositional preference and larval survival on a particular host (Showler and Moran 2003). Increased ovipositional preference for water-stressed plants has been observed in several lepidopteran pests (Wolfson 
1980, Showler and Moran 2003) and may also occur in P. xylostella. Yet, the effects of plant water stress on attraction to insect pests can be complex and variable (Holtzer et al. 1988, Oswald and Brewer 1997). For example, in barley, Hordeum vulgare L., water stress increased attractiveness to Russian wheat aphid, Diuraphis noxia (Mordvilko), but decreased attractiveness to corn leaf aphid, Rhopalosiphum maidis (Fitch), even though both insects have similar feeding strategies (Oswald and Brewer 1997). Larvae feeding on water-stressed plants also have been shown to have reduced growth (Waldbauer 1968, English-Loeb et al. 1997, Showler and Moran 2003; but see Tabashnik 1982, Lewis 1984).

Presence of a repellent or a nonhost could disrupt host finding and subsequent oviposition in P. xylostella. Tomato, labiate herbs, and white clover have been proposed as P. xylostella repellents (Gupta and Thorsteinson 1960; Burunday and Raros 1973; Dover 1985, 1986; Talekar et al. 1986; Bach and Tabashnik 1990). However, experiments to test the repellency of these plants in the field have yielded inconsistent results (Latheff and Irwin 1979, Ivey and Johnson 1998). Intercropping with a nonhost also has been shown to disrupt host finding by $P$. xylostella and other insects, even if the nonhost has no repellent properties (Finch and Collier 2000, Finch et al. 2003).

The focus of this study was to evaluate different cultural and ecological factors that may affect the attractiveness and suitability of hosts for P. xylostella. Hosts known to be highly attractive to P. xylostella were included in this study, such as cabbage, Brassica oleracea L. variety capitata; glossy collards, Brassica oleracea L. variety acephala; and yellow rocket, Barbarea vulgaris (R. Br.) variety arcuata (Badenes-Perez et al. 2004). We hypothesize that planting density, plant age, plant water status, and the presence of a nonhost intercrop may affect host attractiveness and suitability, so these factors were investigated by assessing ovipositional preference and larval survival. Tomato, Lycopersicon esculentum Mill., and fava beans, Vicia fava L., were selected as nonhosts for P. xylostella and were intercropped with cabbage.

\section{Materials and Methods}

Experiments were conducted at the New York State Agricultural Experiment Station in Geneva, NY. P. xylostella used in all experiments originated from a colony collected in 2003 from a cabbage field in Camilla, GA, and maintained on a wheat germ-casein artificial diet (Shelton et al. 1991). The following host cultivars were used in our experiments: 'Bobcat' cabbage (Reed's Seeds, Cortland, NY), 'Green Glaze' collards (Pennington Seed, Madison, GA), and G-type yellow rocket. Yellow rocket seeds were obtained from wild plants growing near Ithaca, NY. Seeds from Green Glaze collards produced both glossy and waxy phenotypes. However, we only used the glossy type in our experiments because it is more attractive to $P$. xylostella (Badenes-Perez et al. 2004). For the intercropping experiment, 'Equina' fava beans (Seedway,
Elizabethtown, PA) and 'New Yorker' tomato (Harris Seeds, Rochester, NY) were selected. All plants used in this study were $12 \mathrm{wk}$ old, except for the experiment comparing the effect of plant age on ovipositional preference and larval survival, which included additional plant ages. All plant types did not flower at the time they were used in the experiments, with the exception of tomato. All plants were grown in 15-cm pots in the greenhouse and were later moved outdoors for at least $2 \mathrm{wk}$ before starting the experiment. Ultimately, plants were moved to screenhouses $24 \mathrm{~h}$ before experimentation. All plants were fertilized weekly with an all-purpose 15-30-15 fertilizer (Wilson Laboratories Inc., Springdale, CT).

General Procedures for Experiments. All experiments were conducted in 4.7 by 3.2 by $2.5-\mathrm{m}$ outdoor screenhouses that were covered with a transparent fiberglass roof. Multiple screenhouses were used, each of which was considered a replicate or block. Ovipositional preference and larval survival experiments were conducted in separate screenhouses.

Ovipositional Preference Experiments. P. xylostella were released at a rate of 1.5 per plant from a plastic container placed on top of two cinder blocks $(80 \mathrm{~cm}$ above ground) located in the middle of the screenhouse. At the release point, a 50-ml Erlenmeyer flask with a $10 \%$ sugar solution and dental wick (Absorbal, Wheat Ridge, CO) was placed as a food source for adults. P. xylostella were released as mated adults, $<2$ $\mathrm{d}$ old, and in a 1:1 sex ratio. Two days after releasing the moths, plants were collected by cutting them from their roots right below the soil level, so eggs laid at the stem base were not disturbed. The number of $P$. $x y$ lostella eggs per plant was counted in the laboratory by using a dissecting microscope.

Larval Survival Experiments. Groups of 10 P. $x y$ lostella eggs ( $<2 \mathrm{~d}$ old $)$ laid on small pieces of aluminum foil were randomly attached with a pin to three of the top four fully expanded leaves of a plant. The same procedure was repeated on three plants, so nine leaves were used in total per treatment $(n=9)$. Larvae of $P$. xylostella were observed every $2 \mathrm{~d}$ until they pupated. Larval survival was recorded as percentage of individuals that reached pupation. The number of days to reach pupation also was recorded. The specific procedures used in each experiment are described in the following sections.

Effect of Planting Density on Ovipositional Preference. Experiments were conducted separately for each plant type (cabbage, glossy collard, and yellow rocket) because we were only interested in evaluating the main effect of planting density for each host. In each screenhouse, two rows of 10 plants each were arranged at a standard planting density $(1 \mathrm{~m}$ between rows and $0.5 \mathrm{~m}$ between plants within rows) on one side of the screenhouse, and at a high planting density $(0.3 \mathrm{~m}$ between rows and $0.2 \mathrm{~m}$ between plants within rows) on the other side of the screenhouse. In total, 60 P. xylostella adults were released in each screenhouse. Treatments were replicated three times for each plant type. 
Effect of Plant Age on Ovipositional Preference. Experiments were conducted separately for each host (cabbage, glossy collards, and yellow rocket). In each screenhouse, five plants of the same age were grouped, so five groups of plants of five different ages $(6,8,10$, 12 , and 14 wk old) were positioned equidistantly from the center of the screenhouse (Fig. 1). Plants formed two concentric circles of 1.0 - and $1.5-\mathrm{m}$ radii, and each plant age treatment was grouped in one of the five $72^{\circ}$ arcs. Plants were arranged in circles to have treatments equally separated from the point from which $P$. xylostella were released and to avoid any possible directional bias. For cabbage, plants of different age corresponded to five consecutive growth stages: growth stage 2 (one to five leaves), growth stage 3 (six to eight leaves), growth stage 4 (nine to 12 leaves), growth stage 5 (13-19 leaves), and growth stage 6 (20-26 leaves) (Andaloro et al. 1983). In total, $38 P$. xylostella adults were released in each screenhouse. The experiment was set as a multiple-choice test and was replicated five times. Total leaf area and number of leaves per plant were quantified by randomly selecting five plants for each host and plant age. The number of leaves and total leaf area were quantified for each plant. Leaf area measurements were taken with a color image analysis system that had an accuracy of $\pm 4 \%$ of the object area measured (model WinDIAS, Delta-T-Devices Ltd., Cambridge, England).

Effect of Plant Age on Larval Survival. Experiments were conducted separately for each plant type (cabbage, glossy collards, and yellow rocket). Larval survival was compared between young (6 wk old) and older plants (12 wk old).

Effect of Water Stress on Ovipositional Preference. This experiment was conducted separately for two plant types, cabbage and yellow rocket. In total, 60 plants were arranged in six rows of 10 plants each in a screenhouse by placing three adjacent rows of water-stressed plants on one side and three adjacent rows of well-irrigated plants on the other side. Well-irrigated plants were watered with $250 \mathrm{ml} / \mathrm{d}$ each. Waterstressed plants were under the same irrigation regime until $1 \mathrm{wk}$ before the beginning of the experiment, when irrigation was first reduced to $125 \mathrm{ml} / \mathrm{d}$ per plant for $4 \mathrm{~d}$ and then eliminated $3 \mathrm{~d}$ before the beginning of the experiment. Water potentials in plants were measured with a pressure bomb (model 3005, Soilmoisture Equipment Corp., Santa Barbara, CA). Plant water status measurements were taken at 3 p.m. by collecting one leaf from the top four fully expanded leaves of 10 randomly selected plants in each treatment. Distance between adjacent rows was $0.5 \mathrm{~m}$, and distance between adjacent plants within rows was $0.3 \mathrm{~m}$. In total, 90 P. xylostella adults were released in each screenhouse. The experiment was conducted as a two-choice test (water-stressed versus well-irrigated plants), and it was replicated three times.

Effect of Water Stress on Larval Survival. Due to the low and zero larval survival of $P$. xylostella larvae on glossy collards and yellow rocket, respectively (Badenes-Perez et al. 2004), only cabbage plants were

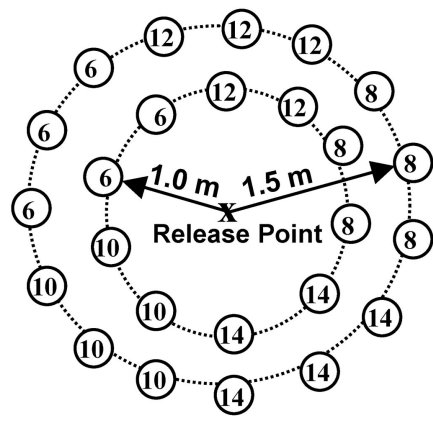

Fig. 1. Arrangement of plants in one of the replicates in experiment testing $P$. xylostella ovipositional preference among plants of five different plant ages $(6,8,10,12$, and 14 wk old).

used in this experiment. Before attaching eggs to leaves, plants were treated as described in the previous experiment. After attaching eggs to leaves, waterstressed plants were only watered every $3 \mathrm{~d}$ with 125 $\mathrm{ml} / \mathrm{d}$ per plant once, whereas well-irrigated plants were watered with $250 \mathrm{ml} / \mathrm{d}$ per plant.

Effect of Tomato and Bean Intercropping on Ovipositional Preference in Cabbage. This experiment included several two-choice tests: 1) cabbage intercropped with tomato plants versus cabbage alone, 2) cabbage intercropped with fava bean plants versus cabbage alone, and 3) cabbage intercropped with tomato versus cabbage intercropped with fava beans. In all treatments, 20 cabbage plants in total were positioned equidistantly in a circle with a $1.5-\mathrm{m}$ radius in a screenhouse, including 10 plants of each of the above-mentioned treatment pairs (Fig. 2). In total, 30 P. xylostella adults were released in each screenhouse. Each two-choice experiment was replicated four times.

Statistical Analyses. Data were analyzed using analysis of variance with the PROC GLM procedure of SAS (SAS Institute 1999). When significant treatment differences were indicated by a significant F-test at $P \leq 0.05$, means were separated by Fisher's protected least significant difference (LSD) (SAS Institute 1999). To determine the relationship between plant age and ovipositional preference, stepwise multiple regression analyses were performed with the PROC REG procedure of SAS (SAS Institute 1999). To normalize the residuals before analysis, data were transformed using a natural $\log (x+1)$ and a square root (x) function for the ovipositional preference and the larval survival tests, respectively. Although all tests of significance were based on the transformed data, only untransformed data are presented.

\section{Results}

Effect of Planting Density on Ovipositional Preference. On average, 2.2 and 1.9 times more eggs were laid in the high than in the standard planting density for glossy collards $(F=8.14 ; \mathrm{df}=1,10 ; P=0.017)$ and yellow rocket $(F=10.29$; $\mathrm{df}=1,10 ; P=0.009)$, 


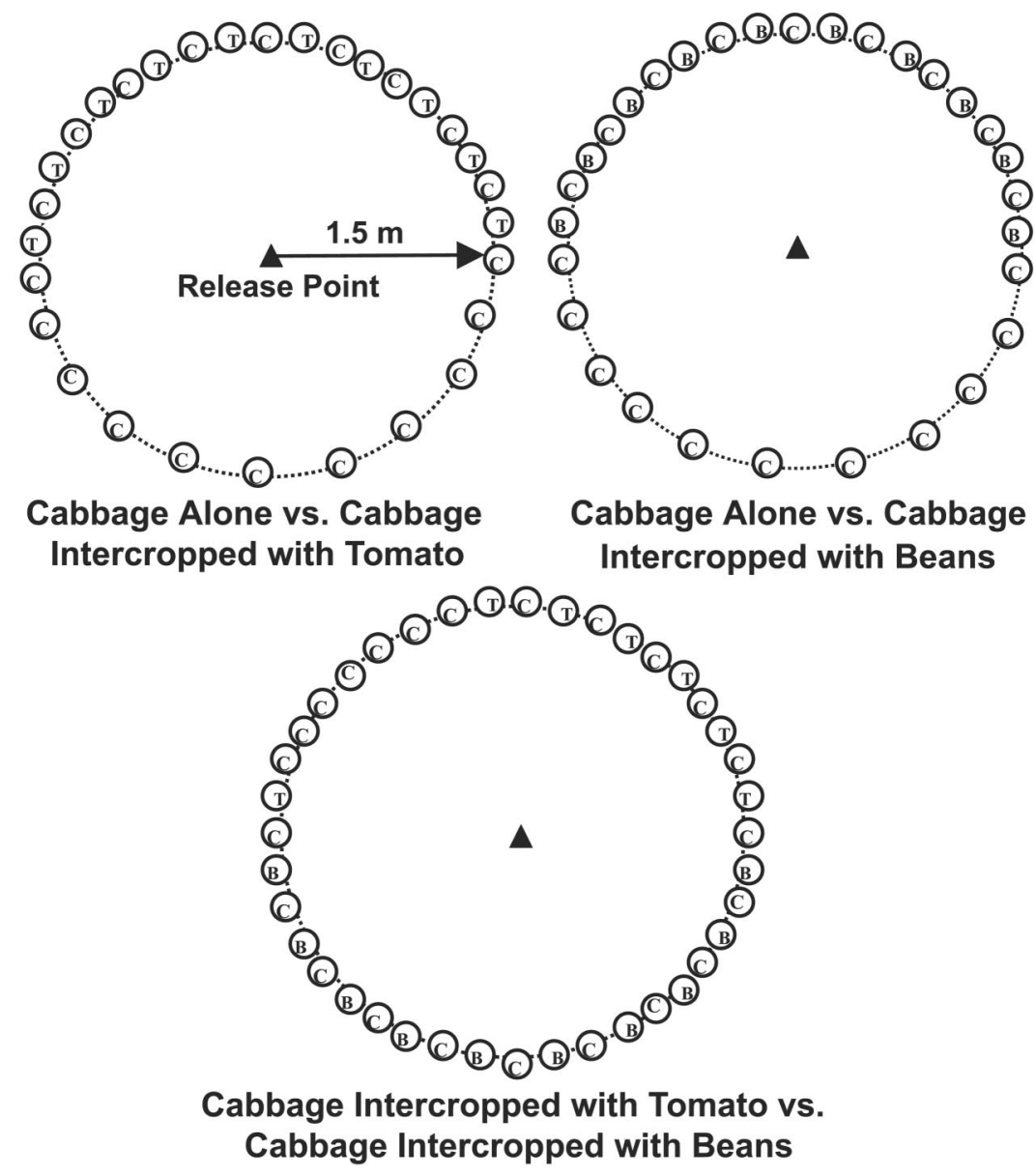

Fig. 2. Diagram of experimental arenas set up to test the effect of tomato (T) and beans (B) intercropping on P. xylostella ovipositional preference in cabbage $(\mathrm{C})$.

respectively (Fig. 3). No significant differences were observed in cabbage $(F=0.29 ; \mathrm{df}=1,10 ; P=0.605)$.

Effect of Plant Age on Ovipositional Preference. Plant age had a significant effect on $P$. xylostella ovipositional preference for all three hosts, cabbage $(F=$
6.56; $\mathrm{df}=4,20 ; P=0.002)$, glossy collards $(F=2.11$ $\mathrm{df}=4,20 ; P=0.018)$; and yellow rocket $(F=25.07$; $\mathrm{df}=4,20 ; P<0.001)$. The relationship between number of eggs laid per plant and increasing plant age was best described using a quadratic function: cabbage

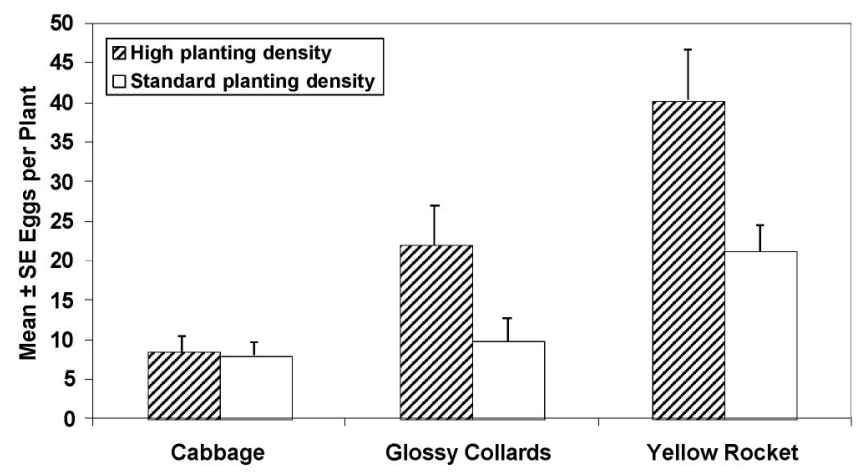

Fig. 3. P. xylostella oviposition on cabbage, glossy collard, and yellow rocket on two different stand densities (high versus standard planting density). Although tests of statistical significance were based on transformed data, the figure shows untransformed data. 


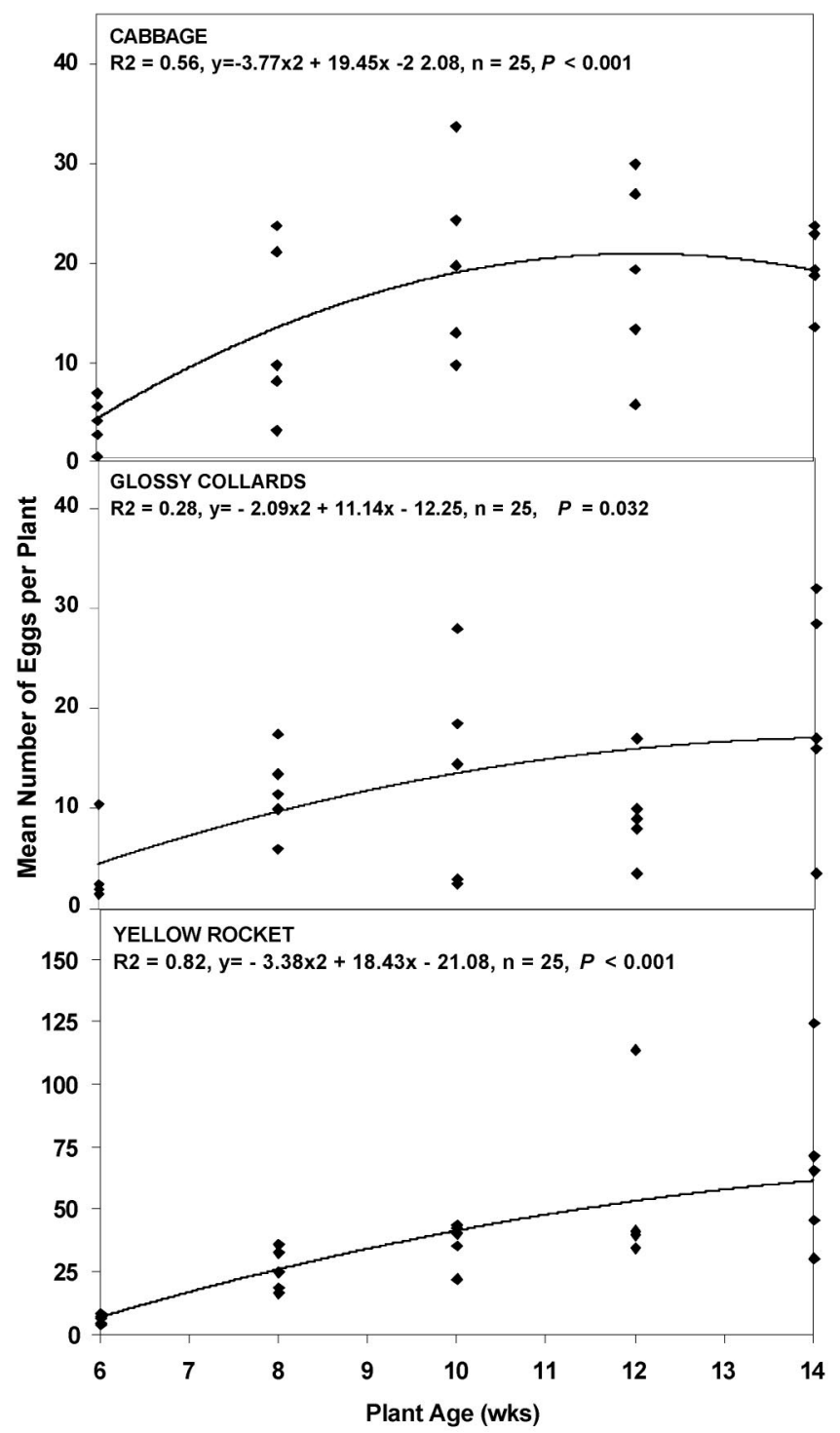

Fig. 4. Regression lines for P. xylostella oviposition on five different plant ages of cabbage, glossy collards, and yellow rocket. Although tests of statistical significance were based on transformed data, the figure shows untransformed data.

$\left(R^{2}=0.56, \mathrm{y}=-3.77 \mathrm{x}^{2}+19.45 \mathrm{x}-22.08, n=25, P<\right.$ $0.001)$, glossy collards $\left(R^{2}=0.28, \mathrm{y}=-2.09 \mathrm{x}^{2}+\right.$ $11.14 \mathrm{x}-12.25, n=25, P=0.032)$, and yellow rocket $\left(R^{2}=0.82, \mathrm{y}=-3.38 \mathrm{x}^{2}+18.43 \mathrm{x}-21.08, n=25, P<\right.$ 0.001 ) (Fig. 4). Increasing plant age also resulted in a significant increase in both number of leaves and total leaf area per plant (Table 1).

Effect of Plant Age on Larval Survival. Survival of $P$. xylostella larvae until pupation was significantly affected by plant age for both cabbage $(F=18.37$; $\mathrm{df}=$ $1,16 ; P<0.001)$ and glossy collards $(F=19.30 ; \mathrm{df}=$ $1,16 ; P<0.001)$. Survival was 1.9 times higher on 6 -wk-old than on 12-wk-old cabbage plants, whereas survival was 12.1 times higher on young glossy collards than on older ones (Fig. 5). No larvae survived on either six or 12-wk-old yellow rocket plants. Time until pupation was significantly affected by plant age $(F=$ 52.78; df $=1,16 ; P<0.001)$, with pupation being reached $1.9 \mathrm{~d}$ earlier on 6 -wk- than on 12 -wk-old cabbage plants (Fig. 6). Time until pupation could not be assessed in the case of glossy collards because of the low sample size (only a total of two larvae reached pupation on all the 12-wk-old plants).

Effect of Water Stress on Ovipositional Preference. Some of the water-stressed plants showed visual signs of water deficit (mild wilting, leaf rolling, and slight discoloration in lower leaves), whereas all the wellirrigated plants looked lush throughout the experiment. The absolute values for the leaf water potential were 2.3 times higher in the water-stressed than on the 
Table 1. Mean $\pm \mathrm{SE}$ total leaf areas and number of leaves per plant on plants of five different ages in cabbage, glossy collards, and yellow rocket

\begin{tabular}{lccc}
\hline Host & $\begin{array}{c}\text { Plant age } \\
(\mathrm{wk})\end{array}$ & No. leaves & $\begin{array}{c}\text { Total leaf area } \\
\left(\mathrm{cm}^{2}\right)\end{array}$ \\
\hline Cabbage & 6 & $4.2 \pm 0.2 \mathrm{a}$ & $72.5 \pm 3.4 \mathrm{a}$ \\
& 8 & $6.8 \pm 0.2 \mathrm{~b}$ & $231.5 \pm 11.0 \mathrm{~b}$ \\
& 10 & $11.8 \pm 0.2 \mathrm{c}$ & $442.6 \pm 25.3 \mathrm{c}$ \\
& 12 & $18.4 \pm 0.4 \mathrm{~d}$ & $1004.3 \pm 29.1 \mathrm{~d}$ \\
Glossy collards & 14 & $25.0 \pm 0.5 \mathrm{e}$ & $1205.0 \pm 50.5 \mathrm{e}$ \\
& 6 & $4.4 \pm 0.2 \mathrm{a}$ & $65.6 \pm 3.2 \mathrm{a}$ \\
& 8 & $6.8 \pm 0.4 \mathrm{~b}$ & $209.7 \pm 9.1 \mathrm{~b}$ \\
& 10 & $11.8 \pm 0.2 \mathrm{c}$ & $387.4 \pm 12.0 \mathrm{c}$ \\
& 12 & $18.6 \pm 0.2 \mathrm{~d}$ & $797.2 \pm 17.5 \mathrm{~d}$ \\
& 14 & $25.4 \pm 0.5 \mathrm{e}$ & $1041.8 \pm 40.3 \mathrm{e}$ \\
& 6 & $3.6 \pm 0.2 \mathrm{a}$ & $12.4 \pm 1.1 \mathrm{a}$ \\
& 8 & $7.6 \pm 0.4 \mathrm{a}$ & $76.9 \pm 4.6 \mathrm{~b}$ \\
& 10 & $22.0 \pm 0.9 \mathrm{~b}$ & $274.0 \pm 16.8 \mathrm{c}$ \\
& 12 & $41.6 \pm 2.1 \mathrm{c}$ & $523.5 \pm 20.4 \mathrm{~d}$ \\
& 14 & $67.6 \pm 4.5 \mathrm{~d}$ & $766.2 \pm 29.4 \mathrm{e}$ \\
\hline
\end{tabular}

For each host, means within a column followed by different letters are significantly different, $P \leq 0.05$ (Fisher's protected LSD; SAS Institute 1999). Although tests of statistical significance were based on transformed data, table shows untransformed data.

well-irrigated cabbage plants $(F=54.95 ; \mathrm{df}=1,18 ; P<$ $0.001)$ and 4.8 times higher on the water-stressed than on the well-irrigated yellow rocket plants $(F=$ $2110.65 ; \mathrm{df}=1,18 ; P<0.001$ ) (Table 2). However, no differences in P. xylostella oviposition occurred between water-stressed and well-irrigated cabbage $(F=$ $3.54 ; \mathrm{df}=1,4 ; P=0.133)$ or yellow rocket plants $(F=$ $4.21 ; \mathrm{df}=1,4 ; P=0.093)$.

Effect of Water Stress on Larval Survival. Survival of $P$. xylostella larvae until pupation was 2.1 times higher on water-stressed than on well-irrigated cabbage plants $(F=19.33$; df $=1,16 ; P<0.001)$ (Table 2 ). The number of days from egg to pupation was reached $2.2 \mathrm{~d}$ earlier on well watered than on waterstressed plants $(F=41.15$; df $=1,16 ; P<0.001)$.

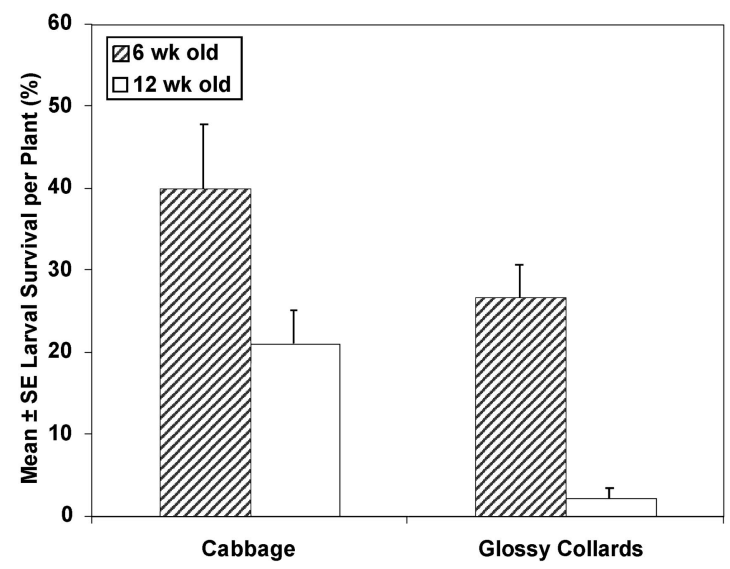

Fig. 5. P. xylostella larval survival from egg to pupal stage on 6- and 12-wk-old plants of cabbage, glossy collards. No larvae reached pupation on yellow rocket. Although tests of statistical significance were based on transformed data, the figure shows untransformed data.

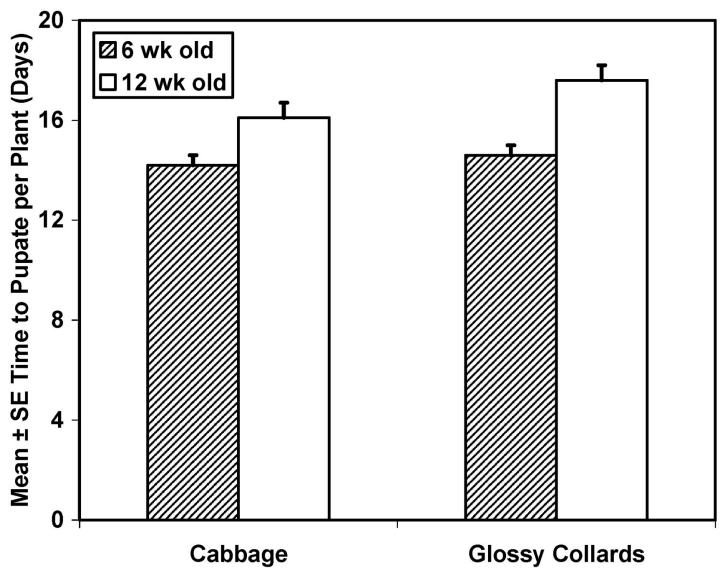

Fig. 6. P. xylostella development from egg to pupal stage (time to pupate) on 6- and 12-wk-old plants of cabbage and glossy collards. No larvae reached pupation on yellow rocket. Although tests of statistical significance were based on transformed data, the figure shows untransformed data.

Effect of Tomato and Bean Intercropping on Ovipositional Preference in Cabbage. Numbers of P. $x y$ lostella eggs laid per cabbage plant were not significantly different in any of the treatment comparisons: cabbage intercropped with tomato versus cabbage alone $(F=1.30 ; \mathrm{df}=1,6 ; P=0.317)$, cabbage intercropped with tomato versus cabbage intercropped with beans $(F=1.96 ; \mathrm{df}=1,6 ; P=0.235)$, and cabbage intercropped with beans versus cabbage alone $(F=$ 4.87; $\mathrm{df}=1,6 ; P=0.092$ ) (Fig. 7).

\section{Discussion}

P. xylostella laid more eggs on the tested cruciferous plants as planting density and plant age. Preference of P. xylostella for dense plant stands and large, more mature plants could be interpreted as an example of the resource concentration hypothesis. An increase in ovipositional preference with increasing plant age may be associated with increasing visual or olfactory stimuli as well as more opportunities for shelter and oviposition sites because of the greater total leaf area and number of leaves. Increased host plant stimuli could be responsible for the increase in oviposition with increasing plant age was most marked in yellow rocket. For example, the increase in number of yellow rocket leaves and total leaf area from 6- to 14-wk-old plants was 18.8- and 61.7-fold, respectively, whereas for glossy collards this increase in number of leaves and total leaf area was only 5.8 and 15.9 , respectively.

The suitability of hosts for P. xylostella larvae increased as plant age decreased. As has been observed in cabbage varieties with reduced wax, the low larval survival of P. xylostella on 12-wk-old glossy collards may be due to behavioral changes of neonate larvae (e.g., increased movement and decreased feeding rates) caused by a reduction in waxes (Eigenbrode and Shelton 1990, 1992). The triterpenoid saponins that have been identified as responsible for P. xylo- 
Table 2. Leaf water potentials and $P$. xylostella oviposition, larval survival, and development from egg to pupal stage on water-stressed vs well-irrigated cabbage and yellow rocket plants

\begin{tabular}{|c|c|c|c|c|c|c|}
\hline \multirow{2}{*}{ Host } & \multicolumn{2}{|c|}{ Leaf water potentials (bar) } & \multicolumn{2}{|c|}{ No. eggs per plant } & \multirow{2}{*}{$\frac{\text { Larval survival }(\%)}{\text { Cabbage }}$} & \multirow{2}{*}{$\frac{\text { Time to pupate }(\mathrm{d})}{\text { Cabbage }}$} \\
\hline & Cabbage & Yellow Rocket & Cabbage & Yellow Rocket & & \\
\hline Water-stressed & $-11.5 \pm 1.0 \mathrm{a}$ & $-20.8 \pm 0.7 \mathrm{a}$ & $4.2 \pm 1.8 \mathrm{a}$ & $6.3 \pm 1.3 \mathrm{a}$ & $12.2 \pm 1.1 \mathrm{a}$ & $14.6 \pm 0.4 \mathrm{a}$ \\
\hline Well-irrigated & $-4.9 \pm 0.2 \mathrm{~b}$ & $-4.3 \pm 0.1 b$ & $10.5 \pm 2.8 \mathrm{a}$ & $8.1 \pm 0.6 \mathrm{a}$ & $25.6 \pm 1.1 b$ & $16.8 \pm 0.4 \mathrm{~b}$ \\
\hline
\end{tabular}

Mean \pm SE, means within a column followed by different letters are significantly different, $P \leq 0.05$ (Fisher's protected LSD; SAS Institute 1999). Although tests of statistical significance were based on transformed data, table shows untransformed data

stella resistance in yellow rocket (Shinoda et al. 2002 , Agerbirk et al. 2003) were likely present in both 6- and 12-wk-old yellow rocket plants because no survival was observed. Zero larval survival of $P$. xylostella on yellow rocket, despite preferential oviposition on this host, has been reported previously (Idris and Grafius 1996, Badenes-Perez et al. 2004, Lu et al. 2004, Shelton and Nault 2004), and it is relevant for the possible use of yellow rocket as a dead-end trap crop (Shelton and Nault 2004). The absence of larval survival on a host that is highly attractive for oviposition has been recorded in other Lepidoptera (Courtney and Kibota 1989, Thompson and Pellmyr 1991, Berdegue et al. 1998).

Plants under water stress have an increased biosynthesis level, which results in the accumulation of free amino acids such as proline, and may be more nutritious for larvae (Chiang and Dandekar 1995, Gzik 1996, Showler 2002, Showler and Moran 2003). However, lack of water also can become a limiting development factor (Showler and Moran 2003). Stomatal closure causes water-stressed plants to become warmer than well-irrigated plants, potentially allowing insects to grow faster (Mattson and Haack 1987b). In our research, the rates of $P$. xylostella larval survival and development on water-stressed plants were lower than on well-irrigated plants, making water-stressed hosts less suitable for $P$. xylostella. A crop under drought conditions may result in an enhanced or reduced attraction to a pest, depending on the particular insect-crop system under study (Mattson and Haack 1987a). Oviposition in lepidopteran pests has been enhanced (Rubberson 1996, Showler and Moran

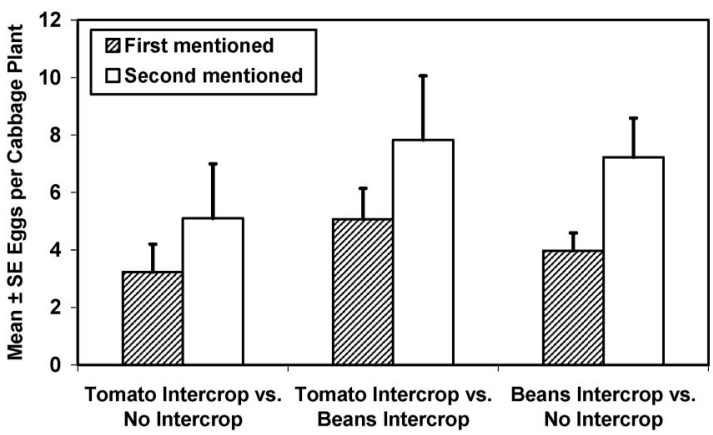

Fig. 7. P. xylostella oviposition on cabbage intercropped with tomato and bean plants. Although tests of statistical significance were based on transformed data, figure shows untransformed data.
2003) or reduced (Slosser 1980) in plants under water stress. Differences in attraction between waterstressed and well-irrigated hosts also may strongly depend on the degree of water-stress examined. In our study, hosts that were water-stressed did not differ from hosts that were well-irrigated in attractivess to $P$. xylostella.

Intercropping cabbage with either tomato or bean plants did not affect the levels of P. xylostella oviposition on cabbage. These results are in agreement with previous studies that did not report a reduction of $P$. xylostella infestations when using tomato plants as an intercrop (Ivey and Johnson 1998). In contrast, other studies have proposed tomato as a P. xylostella repellent (Gupta and Thorsteinson 1960, Burunday and Raros 1973, Talekar et al. 1986, Bach and Tabashnik 1990).

Yellow rocket and glossy collards have good potential as trap crops for $P$. xylostella because they are significantly more attractive than cabbage and larvae do not survive on them as well as on cabbage (Badenes-Perez et al. 2004). Our findings herein provide insight into how these hosts could be manipulated to enhance their attractiveness to P. xylostella. In particular, the trap crop could be planted at higher densities than the main crop, and the trap crop could be planted earlier than the main crop to increase the effectiveness of the trap crop. By planting earlier, the suitability of the glossy collard trap crop could be reduced because the plants would be older at the time they become infested with $P$. xylostella (i.e., larval survival is lower on older than on younger plants). Yellow rocket is the most appealing trap crop because $P$. xylostella larvae do not survive on plants regardless of plant age.

Because planting trap crops may require sacrificing land at the expense of a valuable main crop, a minimum amount of land devoted to trap crop that is sufficient to reduce the target pest population is desired. Integrating the use of higher planting densities in the trap crop than in the main crop and seeding the trap crop earlier than the main crop may reduce the percentage of the field that needs to be devoted to the trap crop to make it effective. However, further studies are needed to test this hypothesis.

\section{Acknowledgments}

We thank Jan Nyrop for helpful suggestions and Hilda Collins for rearing the insects used in our experiments. We also thank Alan Lakso and Rick Piccioni for providing the 
color image analysis system and the pressure bomb to measure total leaf areas and leaf water potentials, respectively. Sarah Bates provided helpful comments on the initial draft of the manuscript. The National Science Foundation Center for Integrated Pest Management (Subcontract No. 1900-000607) and the USDA Pest Management Alternatives Program (Grant No. 2001-34381-11153) provided funding for this study.

\section{References Cited}

Agerbirk, N., C. E. Olsen, B. M. Bibby, H. O. Frandsen, L. D. Brown, J. K. Nielsen, and J.A.A. Renwick. 2003. A saponin correlated with variable resistance of Barbarea vulgaris to the diamondback moth Plutella xylostella. J. Chem. Ecol. 29: 1417-1433.

Andaloro, J. T., K. B. Rose, A. M. Shelton, C. W. Hoy, and R. F. Becker. 1983. Cabbage growth stages, New York's food and life sciences bulletin. Geneva, New York.

Bach, C. E., and B. E. Tabashnik. 1990. Effects of nonhost plant neighbors on population densities and parasitism rates of the diamondback moth (Lepidoptera, Plutellidae). Environ. Entomol. 19: 987-994.

Badenes-Perez, F. R., A. M. Shelton, and B. A. Nault. 2004. Evaluating trap crops for diamondback moth, Plutella xylostella (Lepidoptera: Plutellidae). J. Econ. Entomol. 97: 1365-1372.

Berdegue, M., S. R. Reitz, and J. T. Trumble. 1998. Host plant selection and development in Spodoptera exigua: do mother and offspring know best? Entomol. Exp. Appl. 89: $57-64$.

Burunday, R. P., and R. S. Raros. 1973. Effects of cabbage tomato intercropping on the incidence and oviposition of the diamondback moth, Plutella xylostella (L.). Phillip. Entomol. 2: 369-374.

Chiang, H., and A. Dandekar. 1995. Regulation of proline accumulation in Arabidopsis thaliana (L.) Heynh during development and in response to desiccation. Plant Cell Environ. 18: 1280-1290.

Choi, D. C., J. J. Noh, and K. R. Choe. 2003. Oviposition and feeding preference of the cotton caterpillar, Palpita indica (Lepidopetera: Pyralidae), in Cucurbitacea. Kor. J. Appl. Entomol. 42: 119-124.

Courtney, S. P., and T. T. Kibota. 1989. Mother doesn't know best: selection of hosts by ovipositing insects, pp. 161-188. In E. A. Bernays [ed.], Insect-plant interactions. CRC, Boca Raton, FL.

Dover, J. W. 1985. The response of some Lepidoptera to labiate herb and white clover extracts. Entomol. Exp. Appl. 39: 177-182.

Dover, J. W. 1986. The effect of labiate herbs and white clover on Plutella xylostella oviposition. Entomol. Exp. Appl. 42: 243-247.

Eigenbrode, S. D., and A. M. Shelton. 1990. Behavior of neonate diamondback moth larvae (Lepidoptera: Plutelliadae) on glossy-leaved resistant genotypes of Brassica oleracea. Environ. Entomol 19: 566-571.

Eigenbrode, S. D., and A. M. Shelton. 1992. Survival and behavior of Plutella xylostella larvae on cabbages with leaf waxes altered by treatment with S-ethyl dipropylthiocarbamate. Entomol. Exp. Appl. 62: 139-145.

English-Loeb, G., M. J. Stout, and S. S. Duffey. 1997. Drought stress in tomatoes: changes in plant chemistry and potential nonlinear consequences for insect herbivores. Oikos 79: 456-468.

Finch, S., and R. H. Collier. 2000. Host-plant selection by insects -a theory based on 'appropriate/inappropriate landings' by pest insects of cruciferous plants. Entomol Exp. Appl. 96: 91-102.

Finch, S., H. Billiald, and R. H. Collier. 2003. Companion planting - do aromatic plants disrupt host-plant finding by the cabbage root fly and the onion fly more effectively than non-aromatic plants? Entomol. Exp. Appl. 109: 183195.

Gupta, P. D., and A. J. Thorsteinson. 1960. Food plant relationships of the diamondback moth (Plutella maculipennis [Curt.]). II. Sensory regulation of oviposition of the adult female. Entomol. Exp. Appl. 3: 305-314.

Gzik, A. 1996. Accumulation of proline and pattern alphaamino acids in sugar beet plants in response to osmotic, water, and salt stress. Environ. Exp. Bot. 39: 29-38.

Holtzer, T., T. Archer, and J. Norman. 1988. Host plant suitability in relation to water stress, pp. 111-137. In E. Heinrichs [ed.], Plant stress-insect interactions. Wiley, New York.

Hooks, C.R.R., and M. W. Johnson. 2003. Impact of agricultural diversification on the insect community of cruciferous crops. Crop Prot. 22: 223-238.

Idris, A. B., and E. Grafius. 1996. Effects of wild and cultivated host plants on oviposition, survival, and development of diamondback moth (Lepidoptera: Plutellidae) and its parasitoid Diadegma insulare (Hymenoptera: Ichneumonidae). Environ. Entomol. 25: 825-833.

Ivey, P., and S. Johnson. 1998. Integrating control tactics for managing cabbage looper (Lepidoptera: Noctuidae) and diamondback moth (Lepidoptera: Yponomeutidae) on cabbage. Trop. Agric. 75: 369-374

Kause, A., V. Ossipov, E. Haukioja, K. Lempa, S. Hanhimäki, and S. Ossipova. 1999. Multiplicity of biochemical factors determining quality of growing birch leaves. Oecologia (Berl.) 120: 102-112.

King, B. H., M. L. Crowe, and M. D. Blackmore. 1998. Effects of leaf age on oviposition and on offspring fitness in the imported willow leaf beetle Plagiodera versicolora (Coleoptera: Chrysomelidae). J. Insect Behav. 11: 23-36.

Klemola, T., K. Ruohomäki, M. Tanhuanpää, and P. Kaitaniemi. 2003. Performance of a spring-feeding moth in relation to time of oviposition and bud-burst phenology of different host species. Ecol. Entomol. 28: 319-327.

Larsson, S., and C. P. Ohmart. 1988. Leaf age and larval performance of the leaf beetle Paropsis atomaria. Ecol. Entomol. 13: 19-24

Latheff, M. A., and R. D. Irwin. 1979. The effect of companionate planting on the lepidopteran pests of cabbage. Can. Entomol. 111: 863-864.

Lewis, A. 1984. Plant quality and grasshopper feeding: ef fects of sunflower condition on preference and performance in Melanoplus differentialis. Ecology 65: 836-843.

Leyva, K. J., K. M. Clancy, and P. W. Price. 2000. Oviposition preference and larval performance of the western spruce budworm (Lepidoptera: Tortricidae). Environ. Entomol. 29: 281-289.

Lu, J., Y. B. Liu, and A. M. Shelton. 2004. Laboratory evaluations of a wild crucifer Barbarea vulgaris as a management tool for diamondback moth. Bull. Entomol. Res. 94 $509-516$.

Maguire, L. 1983. Influence of collard patch size on population densities of lepidopteran pests (Lepidoptera: Pieridae, Plutellidae). Environ. Entomol. 12: 1415-1419.

Mattson, W., and R. Haack. 1987a. The role of drought in outbreaks of plant-eating insects. BioScience 37: 110-118.

Mattson, W., and R. Haack. 1987b. The role of drought in provoking outbreaks of phytophagous insects, pp. 365407. In P. Barbosa and J. Schultz [eds.], Insect outbreaks. Academic, London, United Kingdom. 
Oswald II, C., and M. Brewer. 1997. Aphid-barley interactions mediated by water stress and barley resistance to Russian wheat aphid (Homoptera: Aphididae). Environ. Entomol. 26: 591-602.

Poswal, M.A.T., A. D. Akpa, and O. Alabi. 1993. Cultural control of pests and diseases: prelude to integrated pest management practices for resource-poor farmers in $\mathrm{Ni}$ gerian agriculture. J. Sustain. Agric. 3: 5-48.

Raupp, M. J., and R. F. Denno. 1983. Leaf age as a predictor of herbivore distribution and abundance, pp. 91-124. In R. F. Denno and M. S. McClure [eds.], Variable plants and herbivores in natural and managed systems. Academic, New York

Raupp, M. J., J. H. Werren, and C. S. Sadof. 1988. Effects of short-term phenological changes in leaf suitability on the survivorship, growth, and development of gypsy moth (Lepidoptera: Lymantriidae) larvae. Environ. Entomol. 17: $316-319$.

Root, R. B. 1973. Organization of a plant-arthropod association in simple and diverse habitats: the fauna of collards (Brassica oleracea). Ecol. Monogr. 43: 95-124.

Rubberson, J. 1996. Environmental conditions and biological control of the beet armyworm, pp. 116-118. In N. C. Council [ed.], Beltwide Cotton Conference, Memphis, TN.

SAS Institute. 1999. SAS/STAT user's guide, version 8. SAS Institute, Cary, NC.

Shelton, A. M., and B. A. Nault. 2004. Dead-end trap cropping: a technique to improve management of the diamondback moth, Plutella xylostella (Lepidoptera: Plutellidae). Crop Prot. 23: 497-503.

Shelton, A. M., R. J. Cooley, M. K. Kroening, W. T. Wilsey, and S. D. Eigenbrode. 1991. Comparative analysis of two rearing procedures for diamondback moth (Lepidoptera: Plutellidae). J. Entomol. Sci. 26: 17-26.

Shinoda, T., T. Nagao, M. Nakayama, H. Serizawa, M. Koshioka, H. Okabe, and A. Kawai. 2002. Identification of a triterpenoid saponin for a crucifer, Barbarea vulgaris, as a feeding deterrent to the diamondback moth, Plutella xylostella. J. Chem. Ecol. 28: 587-599.

Showler, A. 2002. Effects of water deficit stress, shade, weed competition, and kaolin particle film on selected foliar free amino acid accumulations in cotton, Gossypium hirsutum (L.). J. Chem. Ecol. 28: 631-651.

Showler, A., and P. Moran. 2003. Effects of drought stressed cotton, Gossypium hirsutum L., on beet armyworm, Spo- doptera exigua (Hübner), oviposition, and larval feeding preferences and growth. J. Chem. Ecol. 29: 1997-2011.

Slosser, J. 1980. Irrigation timing for bollworm management in cotton. J. Econ. Entomol. 73: 346-349.

Smyth, R. R., M. P. Hoffmann, and A. M. Shelton. 2003a. Effects of host plant phenology on oviposition preference for Crocidolomia pavonana (Lepidoptera: Pyralidae). Environ. Entomol. 32: 756-764.

Smyth, R. R., M. P. Hoffmann, and A. M. Shelton. 2003b. Larval performance in relation to labile oviposition preference for Crocidolomia pavonana [F.] (Lepidoptera: Pyralidae) among phenological stages of cabbage. Environ. Entomol. 32: 765-770.

Spangler, S. M., and D. D. Calvin. 2000. Influence of sweet corn growth stages on European corn borer (Lepidoptera: Crambidae) oviposition. Environ. Entomol. 29: $1226-1235$.

Tabashnik, B. E. 1982. Responses of pest and non-pest $\mathrm{Co}$ lias butterfly larvae to interspecific variation in leaf nitrogen and water content. Oecologia (Berl.) 55: 389-394

Talekar, N. S., and A. M. Shelton. 1993. Biology, ecology, and management of the diamondback moth. Annu. Rev. Entomol. 38: 275-301.

Talekar, N. S., S. T. Lee, and S. W. Huang. 1986. Intercropping and modification of irrigation method for the control of diamondback moth, pp. 145-151. In N. Talekar [ed.], Diamondback moth management, Proceedings of the First International Workshop, 11-15 March 1985, Tainan, Taiwan. Asian Vegetable Research and Development Center, Shanhua, Taiwan.

Thompson, J. N., and O. Pellmyr. 1991. Evolution of oviposition behavior and host preference in Lepidoptera. Annu. Rev. Entomol. 36: 65-89.

Tollsten, L., and G. Bergstrom. 1988. Headspace volatiles of whole plants and macerated plant parts of Brassica and Sinapis. Phytochemistry 27: 2073-2077.

Waldbauer, G. 1968. The consumption and utilization of food by insects. Advance Insect Physiol. 5: 229-288.

Watt, A. D. 1987. The effect of shoot growth stage of Pinus contorta and Pinus sylvestris on the growth and survival of Panolis flammea larvae. Oecologia (Berl.) 72: 429-433.

Wolfson, J. 1980. Oviposition response of Pieris rapae to environmentally induced variation in Brassica nigra. Entomol. Exp. Appl. 27: 223-232.

Received 25 September 2004; accepted 28 January 2005. 